Sains Malaysiana 50(11)(2021): 3405-3420

http://doi.org/10.17576/jsm-2021-5011-24

\title{
Wavelet Characterizations for Investigating Nonlinear Oscillators
}

(Pencirian Gelombang Kecil untuk Mengakaji Pengayun Tak Linear)

\author{
Mohd Aftar Abu Bakar, Noratiqah Mohd ArifF*, Andrew V. Metcalfe \& David A. Green
}

\begin{abstract}
This study investigates the wavelet-based system identification capabilities on determining the system nonlinearity based on the system impulse response function. Wavelet estimates of the instantaneous envelopes and instantaneous frequency are used to plot the system backbone curve. This wavelet estimate is then used to estimate the values of the parameter for the system. Two weakly nonlinear oscillators, which are the Duffing and the Van der Pol oscillators, have been analyzed using this wavelet approach. A case study based on a model of an oscillating flap wave energy converter (OFWEC) was also discussed in this study. Based on the results, it was shown that this technique is recommended for nonlinear system identification provided the impulse response of the system can be captured. This technique is also suitable when the system's form is unknown and for estimating the instantaneous frequency even when the impulse responses were polluted with noise.
\end{abstract}

Keywords: Nonlinear oscillator; system identification; wavelet; wave energy converter

ABSTRAK

Penyelidikan ini telah mengkaji kemampuan pengecaman sistem berasaskan gelombang kecil untuk menentukan ketaklinearan sesuatu sistem berdasarkan fungsi sambutan dedenyut sistem tersebut. Anggaran sampul seketika dan frekuensi seketika oleh penganggar gelombang kecil digunakan untuk memplot lengkung tulang belakang sistem tersebut. Penganggar gelombang kecil ini digunakan untuk menganggarkan nilai parameter bagi sistem tersebut. Dua jenis pengayun tak linear, iaitu pengayun Duffing dan Van der Pol, telah dianalisis menggunakan kaedah ini. Satu kajian kes berdasarkan model penukar tenaga ombak jenis pengayun berkibas (OFWEC) turut dibincangkan dalam kajian ini. Berdasarkan keputusan yang diperoleh, didapati bahawa teknik ini sesuai digunakan untuk pengecaman sistem tak linear apabila sambutan dedenyut sistem tersebut boleh diperoleh. Teknik ini juga sesuai digunakan apabila bentuk sesuatu sistem itu tidak diketahui dan juga untuk menganggarkan frekuensi serta-merta walaupun dedenyut sistem dicemari dengan hingar.

Kata kunci: Gelombang kecil; pengayun tak linear; pengecaman sistem; penukar tenaga ombak

\section{INTRODUCTION}

The purpose of system identification is to determine a mathematical relation between the system's observed behaviours or responses (outputs) and the external influences or forces on the system (inputs). The system can be described using the mathematical models since the dynamic behaviour of a system or process is observed in either the time domain or the frequency domain. Identification of a nonlinear system usually involves the estimation of instantaneous frequencies and amplitudes of the system. The instantaneous modal parameters, such as the stiffness and damping, can then be estimated using the estimated instantaneous frequency and amplitudes.
In the past, Fourier transform has been the primary tool for analysis and identification of the linear and nonlinear dynamic system. However, it has some limitations in analyzing time-variant models and parameters since it is conducted in the frequency domain. Deep learning techniques such as the Long Short-term Memory (LSTM), based on the Recursive Neural Network, have gained some attention for system identification (Wang 2017; Woo et al. 2018).

Wavelet transforms (WT) have a potential advantage of displaying frequency composition over time. Wavelet has been used for system identification especially for structural health monitoring (Perez-Ramirez et al. 2017; 
Pirboudaghi et al. 2018), control systems (Moradi et al. 2019; Swaidan \& Hussin 2016) and identifying modal parameters (Lin \& Lin 2020; Zhang et al. 2019). Since wavelet is localized in the time-scale domain, certain information can be accessed directly and immediately from the wavelet representation of a time series (Mohammed et al. 2020). This multi-scale feature of wavelet transforms can validate a dynamic model from a continuous wavelet transform of the process observations and model time series data (McCusker et al. 2010).

Several studies have used wavelet for system identification to analyse ship roll and heave-roll coupling (Yu et al. 2006). Pernot and Lamarque (2001) have used wavelet to compute parametrically excited dynamic systems' transient responses. Meanwhile, Gouttebroze and Lardies (2001) used the wavelet identification technique to identify structural systems' characteristics by analyzing the amplitude and phase of a wavelet transform for vibration data. Bakar et al. (2012) have shown that wavelet can estimate the transfer function for linear systems with noisy signals. Other wavelets applications include solving differential equations, turbulence analysis, image processing, and signal processing (Hardle et al. 1998).

The usual wavelet approach to identify and estimate a nonlinear oscillator's parameters is by estimating the wavelet ridge and the wavelet backbone from the impulse response (IRF) (Londoño et al. 2015; Spina et al. 1996; Staszewski 1998). The wavelet backbone is a plot of instantaneous frequency against the amplitude. The wavelet backbone is just a straight line for a single degree of freedom linear oscillator since the instantaneous frequency does not vary with amplitude. The main limitation of this approach is it may not be feasible to obtain the impulse response outside of laboratory conditions. Therefore, a segment averaging technique, known as the random decrement technique (RDT), has been proposed to obtain an estimate of an impulse response from a record of the response to arbitrary forcing (Kijewski \& Kareem 2003; Ruzzene et al. 1997). However, the segment averaging technique is only suitable for a linear system, since a nonlinear system's response is chaotic.

This paper aims to investigate how wavelet characterization can be applied to estimate the parameters of nonlinear oscillators. This study shows that wavelet ridge methods can be used to identify particular types of nonlinearity. Three types of nonlinear oscillators systems were analyzed, which are the Duffing, the Van der Pol, and a system that allows for both inertial forces and drag forces on cylinders subject to wave forces. We refer to the last-mentioned system as a Morison system because it is typically modelled with Morison's equation (Bakar et al. 2014; Folley et al. 2007; Whittaker \& Folley 2012). Comparison between this wavelet-based system identification technique with the Hilbert's based technique for cases with and without noise was also presented in this study.

This paper is arranged in the following order. In the next section, we give the general theory on the wavelet identification technique for nonlinear oscillators. The third section discusses the application on two weakly nonlinear oscillators. The case study is then discussed and ended with conclusions and discussions.

\section{NONLINEAR SYSTEM IDENTIFICATION BY WAVELET RIDGE WAVELET TRANSFORM}

The continuous wavelet transform (CWT) of a signal $x(t)$ at time $b$ and scale $a$ can be defined as

$$
T_{x}(a, b)=\frac{1}{a} \int_{-\infty}^{\infty} x(t) \Psi^{*}\left(\frac{t-b}{a}\right) d t
$$

where

$$
\psi_{(a, b)}(t)=\frac{1}{a} \psi\left(\frac{t-b}{a}\right)
$$

is the wavelet function. Here, $T_{x}(a, b)$ are known as the wavelet coefficients, which provide information about the signal, $x(t)$, at scale $a$ and around time $b$. A wavelet function must satisfy the conditions:

$$
\int_{-\infty}^{\infty} \psi(t) d t=0 \text { and } \int_{-\infty}^{\infty} \psi^{2}(t) d t=1 .
$$

Wavelet transforms preserves the energy of the process and it can be shown that

$$
\int_{-\infty}^{\infty} x^{2}(t) d t=\frac{1}{C_{\psi}} \int_{0}^{\infty}\left[\int_{-\infty}^{\infty} T_{x}^{2}(a, b) d b\right] \frac{d a}{a^{2}},
$$

where

$$
C_{\psi}=\int_{0}^{\infty} \frac{|\Psi(\omega)|}{\omega} d \omega
$$

and $\Psi(\omega)$ is the Fourier transform of $\psi(\cdot)$, provided $0<C_{\psi}<\infty$ (wavelet admissible condition). The inverse CWT is defined as

$$
x(t)=\frac{1}{C_{\psi}} \int_{0}^{\infty} \frac{1}{\sqrt{a}}\left[\int_{-\infty}^{\infty} T_{x}(a, b) \psi\left(\frac{b-t}{a}\right) d b\right] \frac{d a}{a^{2}} .
$$


Here we use the Morlet wavelet which is defined as

$$
\psi(x)=\exp \left(-\frac{x^{2}}{2 \sigma^{2}}\right) \exp \left(i \omega_{0} x\right)
$$

where $\sigma$ and $\omega$ are parameters that control the size of the wavelet envelope and oscillations, respectively. The Morlet wavelet is a modulated Gaussian function and its integral is approximately zero for $\sigma \omega_{0}>5$. The Fourier transform of the Morlet wavelet is

$$
\Psi(\omega)=\exp \left(-\frac{(\omega-2 \pi)^{2}}{2}\right),
$$

which provides good localization in the frequency domain (Carmona et al. 1997; Staszewski 1998).

In the CWT, the coefficients have the dimension of seconds. However, the frequency corresponding to scale $a$ is given by the relationship

$$
f_{a}=\frac{f_{c}}{a \cdot \Delta},
$$

where $f_{a}$ is the frequency related to scale $a ; f_{c}=\frac{\omega_{0}}{2 \pi}$ is the wavelet central frequency; $a$ is the scale; and $\Delta$ is the signal sampling interval (Staszewski 1998).

\section{INSTANTANEOUS MODAL PARAMETERS}

The impulse response of an oscillating system, $y(t)$, can be converted to its analytic signal form by applying the Hilbert transform (Feldman 1994). The instantaneous modal parameters, the instantaneous envelope, and instantaneous phase, can be extracted from the analytic signal. For a linear system, the instantaneous natural frequency and instantaneous damping coefficient, which determine the phase, are constant over time. However, if the system has nonlinear stiffness, the natural frequency will vary over time since it depends on the amplitude of vibrations. Using the backbone curve, which is the plot of the signal instantaneous envelope on the instantaneous frequency, the nonlinearity can be identified. Nonlinearity in the damping can also be identified from the instantaneous envelope.

Assume a general autonomous SDOF weakly nonlinear oscillator

$$
\ddot{y}_{t}+D(\dot{y})+S(y)=0,
$$

where $D(\dot{y})$ and $S(y)$ are the dissipative and restoring force function, respectively. The instantaneous envelope,
$A(t)$, and instantaneous frequency, $\omega(t)$, can be approximated using the Krylov and Bogoliubov method (Nayfeh 2008). Different types of nonlinear oscillator have unique forms for their modal parameters (Feldman 1994).

\section{WAVELET RIDGE}

Carmona et al. (1997) introduced a technique to detect ridges in the modulus of the CWT. A wavelet ridge is the localization of the signal in the time-frequency domain, which is vital in nonlinearity detection and useful in analyzing noisy signals (Carmona et al. 1998, 1997). Staszewski (1997) estimated the damping ratio of the impulse response for linear multi-degree of freedom systems by using the wavelet ridges and skeletons and applied this technique to the identification of nonlinear MDOF systems (Staszewski 2000, 1998). Meanwhile, Londoño et al. (2015) proposed an alternative technique to identify a nonlinear system's backbone curves from an impulse response.

The wavelet ridge at time $t$ can be obtained by identifying the global maxima of the CWT modulus. If there is more than one ridge, the local maxima of the CWT modulus can be used. However, it will be problematic to identify the local maxima representing the actual wavelet ridge if there is noise in the signal and if the frequency of each of the ridges is close to one another.

For a signal with relatively low noise, the differentiation technique such as Newton's method can be used to identify the wavelet ridge. However, this approach will not be suitable for the case of significant noise or when the identified ridge is not a smooth function.

The original signal (in the time domain) can be reconstructed based on the wavelet skeleton (Carmona et al. 1998). However, information on the CWT on the ridge was required, which is computationally expensive, especially if there are many ridges. However, it is still more efficient compared to reconstructing the original signal by using all the original wavelet coefficients.

\section{SYSTEM IDENTIFICATION TECHNIQUE BASED ON WAVELET RIDGE}

Let the impulse response of the oscillating system, $y(t)$, be written as

$$
y(t)=A(t) \exp (i \phi(t))
$$


From the impulse response, the wavelet ridges can be identified from its CWT. The oscillating system's instantaneous envelope and the instantaneous frequency can then be computed from the wavelet skeleton and wavelet ridge, respectively. The CWT of the impulse response can be computed using numerical integration with the 'Rwave' (Carmona 2018) package in R.

Following Londoño et al. (2015), the system's damping can be estimated from the slope of the semilogarithmic plot of the instantaneous envelope against time. The plot of the instantaneous frequency against the instantaneous envelope will produce the system backbone curve. The system's nonlinearity can then be identified and categorized using the estimated backbone curve and the estimated damping ratios (Londoño et al. 2015; Staszewski 1998). Given that we know the type of system, we can use these instantaneous characteristics to estimate the system parameters (refer to Table 1 in Spina et al. (1996)).

\section{APPLICATION OF THE WAVELET TECHNIQUE}

We perform the wavelet method to identify the Duffing and Van der Pol oscillators' parameters from the impulse response. We demonstrate that this method can also be used with a wave tank input (Bakar et al. 2012) provided the input and the output signals are measured. Although the wavelet method requires an impulse response, it may be possible to estimate this from a system response to an arbitrary input by the random decrement technique (RDT) (Kijewski \& Kareem 2003; Ruzzene et al. 1997).

The RDT averages the responses of the system following a trigger event, such as the displacement being within a small distance of some specified value.
It is necessary to consider whether the initial velocity is positive or negative by noting whether the next displacement is greater than or less than the specified value. The RDT is theoretically justified for linear systems but is at best an approximation for a nonlinear system precisely because the systems are nonlinear. In the Duffing and Van der Pol oscillators cases, the RDT did not converge, presumably because the forced response is chaotic (Strogatz 2000).

\section{DUFFING OSCILLATOR}

The Duffing system has been selected as an example of a system with nonlinear stiffness. The SDOF Duffing system can be modelled as

$$
m \ddot{y}_{t}+c \dot{y}_{t}+k y_{t}+k_{3} y_{t}^{3}=x_{t},
$$

where $y_{t}$ is the response (output); $x_{t}$ is the force (input); $m$ is the inertial mass; $c$ is the damping coefficient; $k$ is the stiffness coefficient and $k_{3}$ is the nonlinear feedback cubic stiffness coefficient. For this example, we have selected $m=1, c=0.005, k=1$ and $k_{3}=100$. By discretizing the continuous-time model using the central differences (Bakar et al. 2013), the impulse response of this Duffing system can be approximated by

$$
y_{t} \approx \frac{\left(\frac{2 m}{\Delta^{2}}-k\right) y_{t-1}+\left(\frac{c}{2 \Delta}-\frac{m}{\Delta^{2}}\right) y_{t-2}-k_{3} y_{t-1}^{3}+x_{t-1}}{\frac{m}{\Delta^{2}}+\frac{c}{2 \Delta}} .
$$

Then, the impulse response was simulated using the Runge-Kutta $4^{\text {th }}$ order method such as plotted in Figure 1.

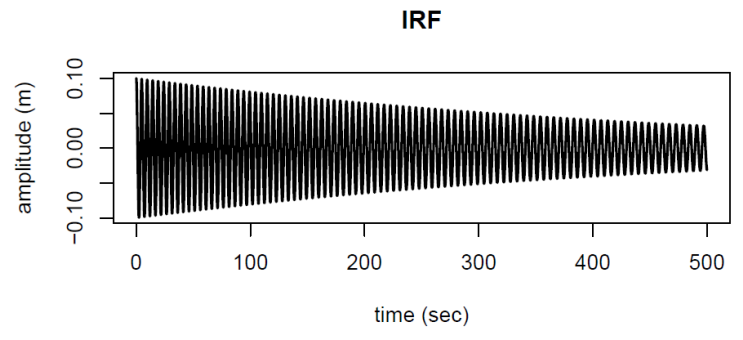

(a) First 500 seconds

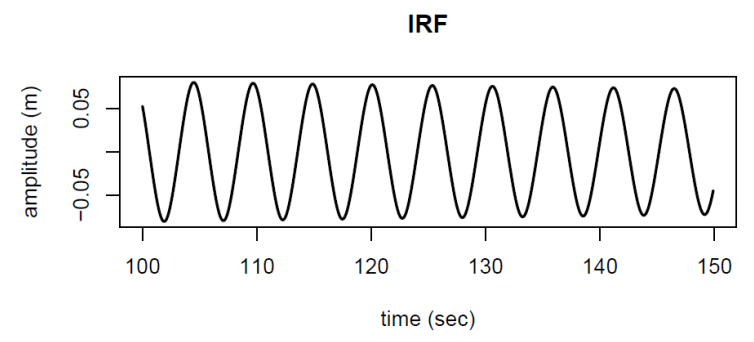

(b) Samples of 100 to 150 second

FIGURE 1. Time series of the impulse response (IRF) for the Duffing system 


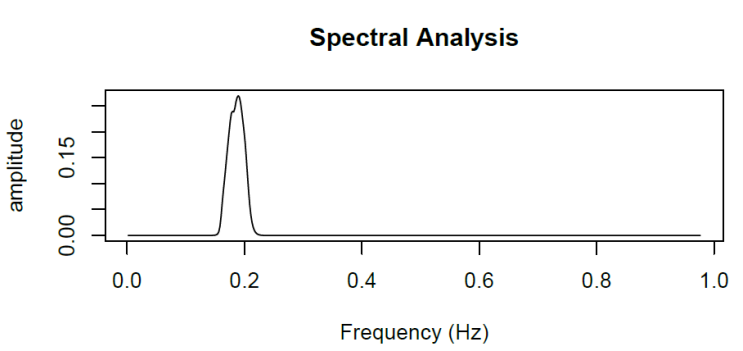

(a) Fourier transorm of impulse response

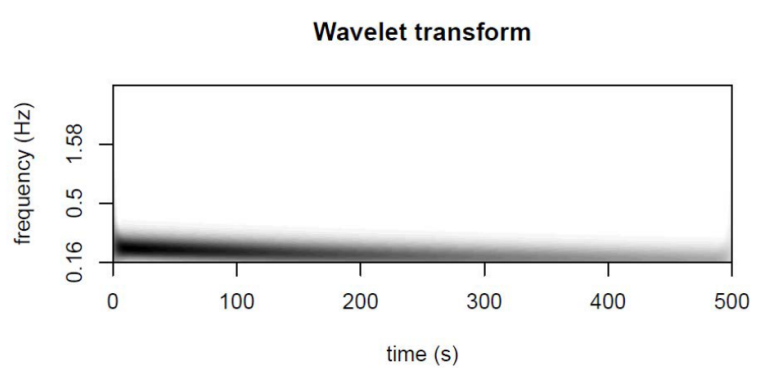

(b) Wavelet transform of impulse response

FIGURE 2. Spectral analysis and CWT of the impulse response (IRF) for the Duffing system

It can be seen from Figure 2, that the CWT of the impulse response can capture the change of the impulse response's frequency over time while the spectral analysis only averages the frequencies. The estimated instantaneous frequency from the wavelet ridge is plotted in Figure 3(a) together with that estimated with the Hilbert transform and the theoretical instantaneous frequency. Both the wavelet and Hilbert estimation of the instantaneous envelope for this Duffing system fits the impulse response's peak, such as shown in Figure 3(b). Moreover, the reconstructed impulse response from the wavelet skeleton is similar to the original impulse response (Figure 4).

\section{Instantaneous Frequency}

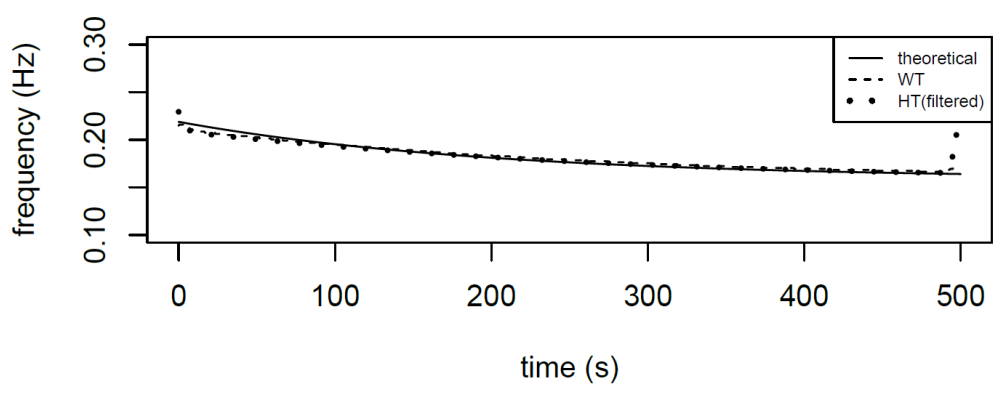

(a) Instantaneous frequency of the impulse response

IRF and Instantaneous Envelope

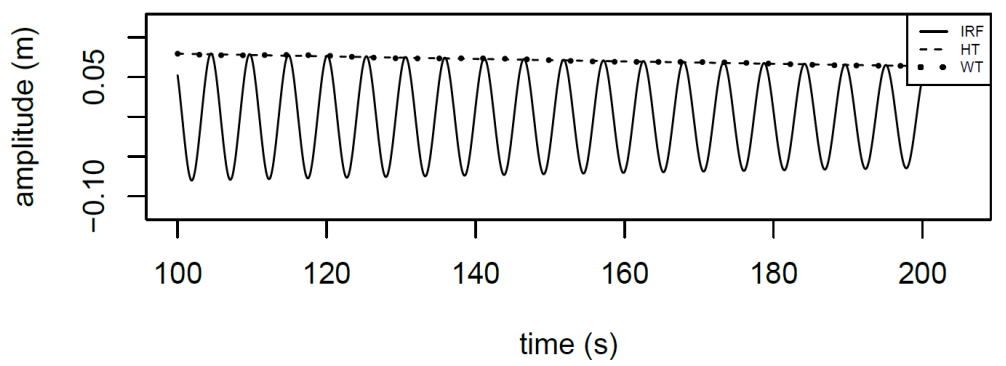

(b) Actual impulse response (full line) and instantaneous envelope (dashed line)

FIGURE 3. Wavelet estimation for the Duffing system with an impulse input 
IRF

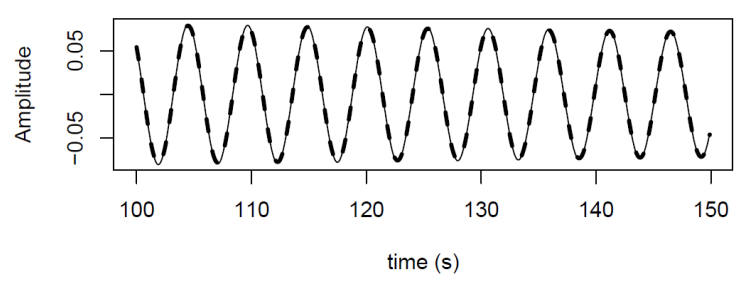

FIGURE 4. Theoretical (full line) and estimated (dashed line) the impulse response (IRF) for the Duffing system at 100 to 150 second

We use the slope of the tangent of the semilogarithmic plot of instantaneous envelope against time in Figure 5 to estimate the damping coefficient of this Duffing system. The estimate of the damping coefficient is $\hat{c}=0.0046$, while the theoretical value from the model is 0.005 . We estimated both $k$ and $k_{3}$ from the estimated instantaneous frequency and envelopes of the impulse response by fitting them to the approximated instantaneous frequency function from Table 1 in Spina et al. (1996). The estimated ratio, $k_{3} / \sqrt{k}$ is 89.056 , while the ratio from the model, is equal to 100 .

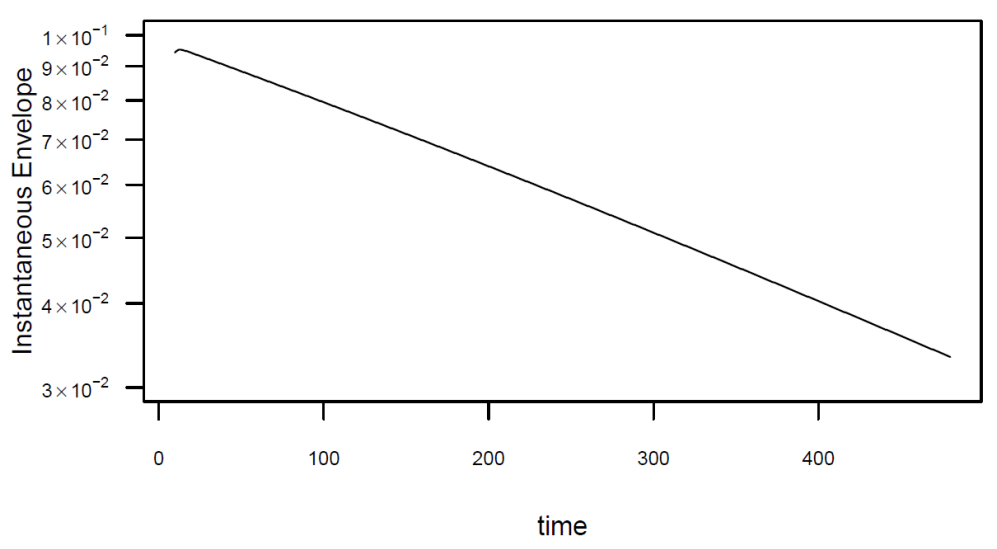

FIGURE 5. The semi-logarithmic plot of the instantaneous envelopes against time for the Duffing system

\section{Backbone}

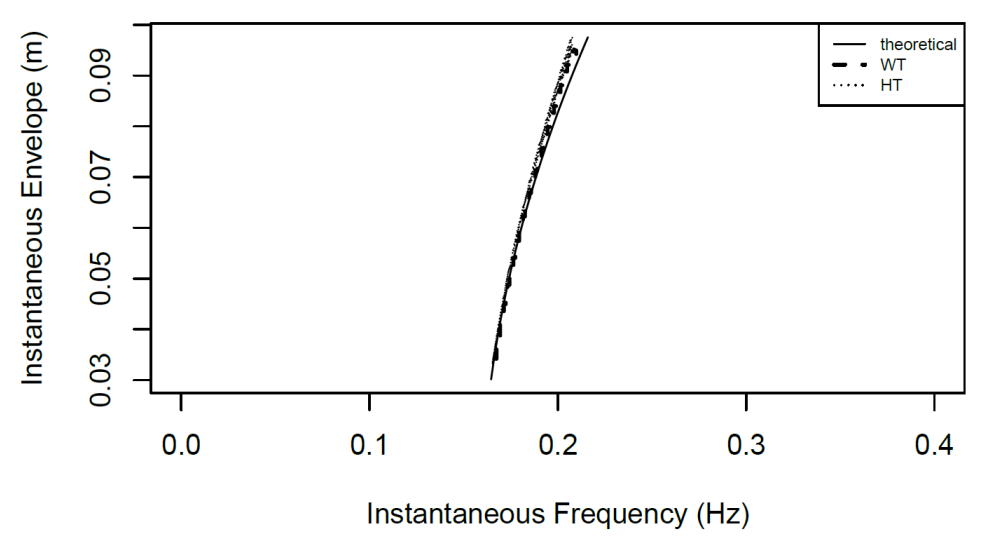

FIGURE 6. Theoretical and estimated backbone curves for the Duffing system 
It can be seen that for the system with nonlinear stiffness, the plot of wavelet estimated backbone in Figure 6 is not a straight line. This is similar to the theoretical backbone and the estimated backbone using the Hilbert transform. This shows that the frequency depends on the response amplitude.

\section{VAN DER POL OSCILLATOR}

The Van der Pol system has been selected as an example of a system with nonlinear damping. The SDOF Van der Pol model can be written as

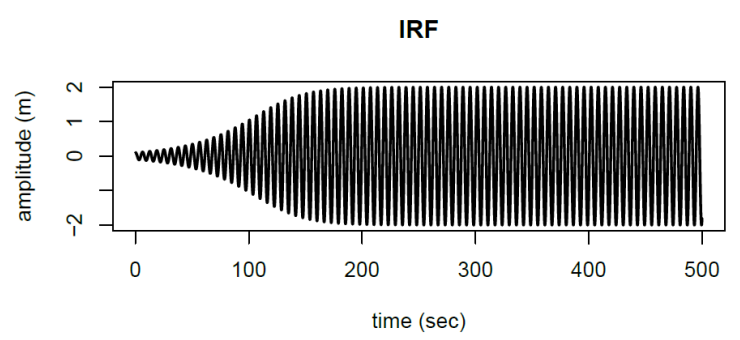

(a) First 500 seconds

$$
\ddot{y}_{t}+\mu\left(y_{t}^{2}-1\right) \dot{y}_{t}+y_{t}=x_{t}
$$

where $y_{t}$ is the response (output); $x_{t}$ is the force (input); and $\mu$ is the nonlinear damping coefficient. For this example, we have selected $\mu=0.05$. Similar to the previous oscillator, the impulse response of this Van der Pol system (Figure $7 \& 8$ ) has been simulated by using the Runge-Kutta method.

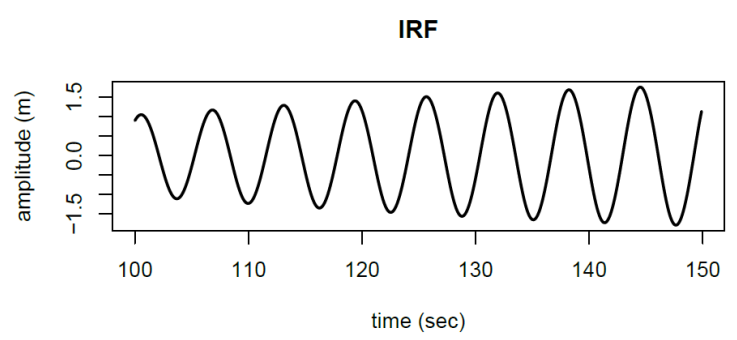

(b) Samples of 100 to 150 second

FIGURE 7. The impulse response (IRF) time series for the Van der Pol system

Spectral Analysis

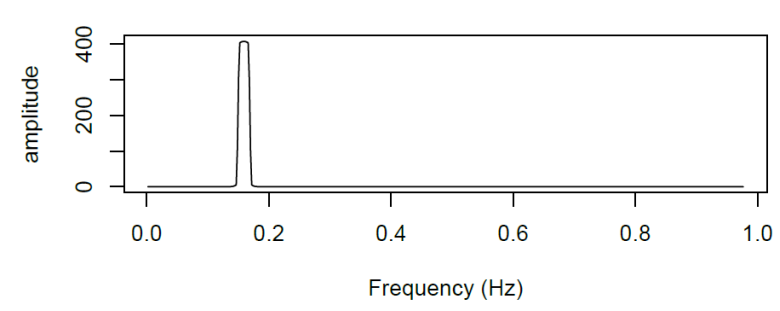

(a) Fourier transorm of impulse response

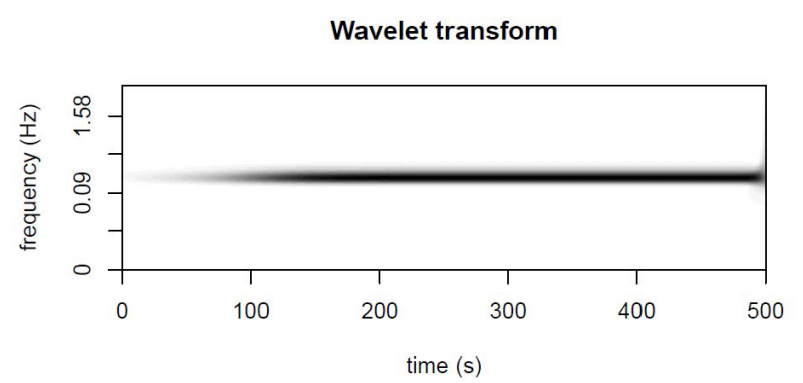

(b) Wavelet transform of impulse response

FIGURE 8. Spectral analysis and CWT of the impulse response (IRF) for the Van der Pol system

The wavelet estimated instantaneous frequency in Figure 9(a) shows that this Van der Pol system's frequency does not change over time. The wavelet estimated instantaneous envelope does capture the peak of the impulse response (Figure 9(b)) and the reconstructed impulse response, based on the wavelet skeleton, does fit the original impulse response (Figure 10).

For this Van der Pol system, the damping varies over time. The damping is geometrically equivalent to the slope of the tangent of the curve in the semi-logarithmic plot of the instantaneous envelope against time as in Figure 11, and it can be seen to increase to a threshold value over time. Based on the Van der Pol system's wavelet estimated backbone curve (Figure 12), we can say that the response amplitude does not depend on the frequency.

We use the Nelder-Mead method (Olsson \& Nelson 1975 ) to find the estimated value of the nonlinear damping 


\section{Instantaneous Frequency}

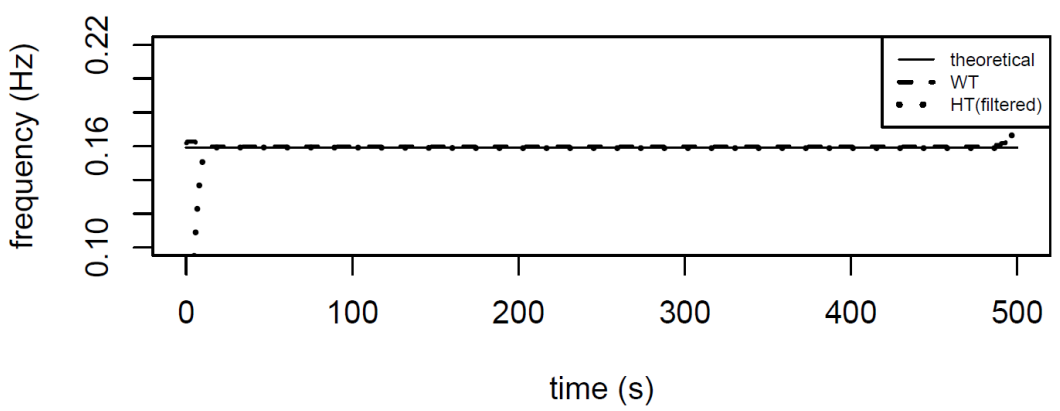

(a) Instantaneous frequency of the impulse response

\section{IRF and Instantaneous Envelope}

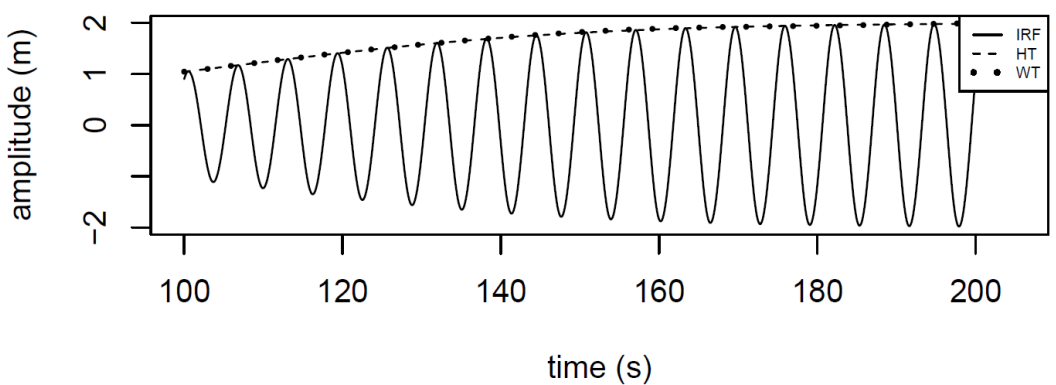

(b) Actual impulse response (full line) and instantaneous envelope (dashed line)

FIGURE 9. Wavelet estimation for the Van der Pol system with an impulse input

IRF

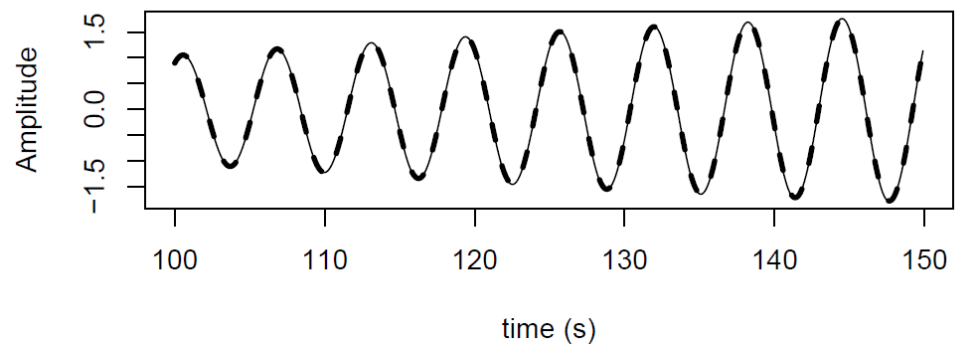

FIGURE 10. Theoretical (full line) and estimated (dashed line) the impulse response (IRF) for the Van der Pol system from 100 to 150 second

coefficient, $\mu$, from the impulse response's estimated envelopes. The estimated value, $\hat{\mu}$, is found to be 0.0499 , which is close to 0.05 , the theoretical value from the Van der Pol model. 


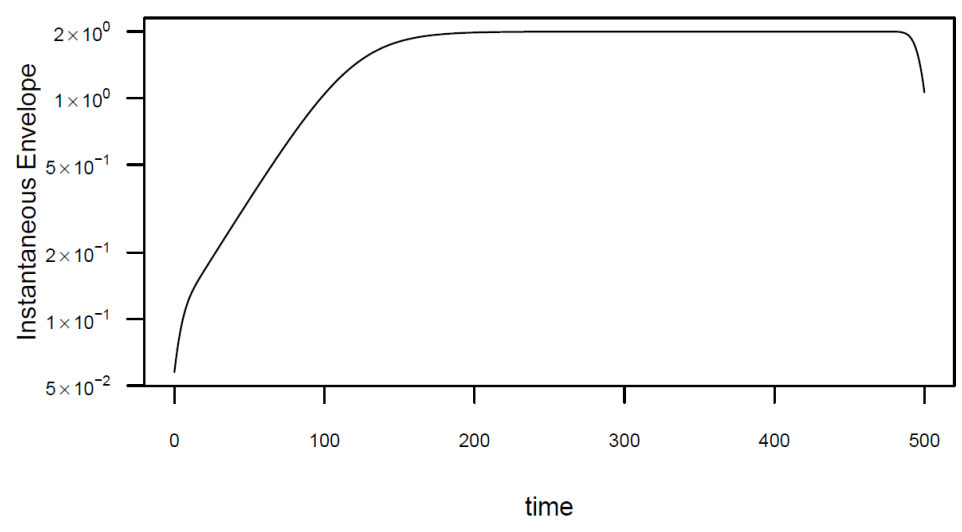

FIGURE 11. The semi-logarithmic plot of the instantaneous envelopes against times for the Van der Pol system

\section{Backbone}

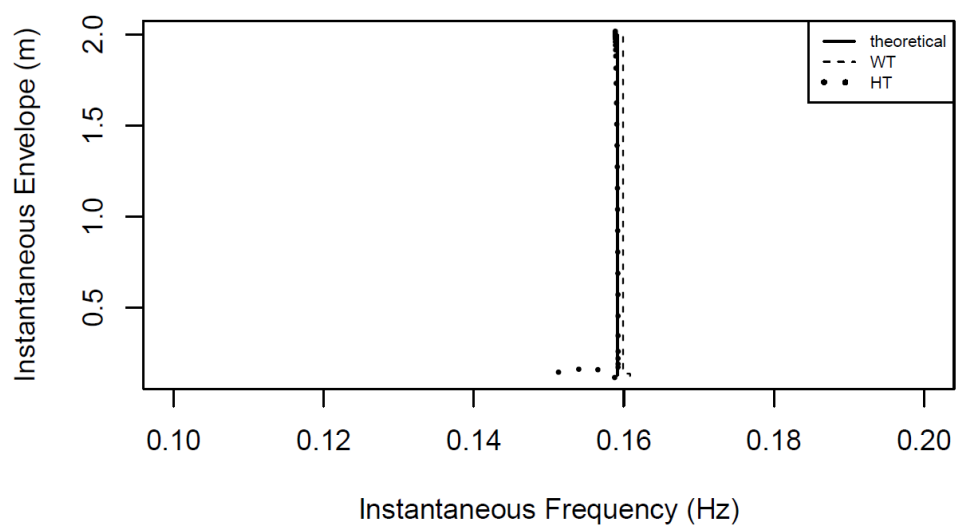

FIGURE 12. Theoretical and estimated backbone curves for the Van der Pol system

\section{CASE STUDY}

In this case study, we apply this technique to identify an oscillating flap wave energy converter (OFWEC) dynamic system. An OFWEC, such as shown in Figure 13 , is an SDOF dynamic system, but with a surge mode of vibration in response to the wave surge force. According to Folley et al. (2007), assuming the motion of the flap is sinusoidal, the nonlinear dynamic system for an OFWEC can be modelled as

$$
\left(I+I_{a}\right) \ddot{\theta}_{t}+k_{p} \theta_{t}+\left(\Lambda+B_{r}\right) \dot{\theta}_{t}+B_{v}\left|\dot{\theta}_{t}\right| \dot{\theta}_{t}=F_{t} \cos \theta_{t}
$$

where $F_{t}$ is the wave surge force at time $t ; \theta_{t}$ is the angular rotation of the body at time $t ; I$ is the body moment of inertia; $I_{a}$ is the added moment of inertia; $k_{p}$ is the pitch stiffness of the body; $\Lambda$ is the power takeoff damping coefficient; $B_{r}$ is the radiation damping coefficient and $B_{v}$ is the viscous damping coefficient. Equation 15 is equivalent to the second-order differential equation of a linear mass-spring system with an additional nonlinear term for the torque induced by vortex-shedding, which is usually approximated by the instantaneous velocity squared. This instantaneous velocity squared is known as the drag term from the Morison equation (Morison et al. 1950), resulting in the model being considered a nonlinear model. This nonlinear damping causes the response's amplitude to be slightly reduced (Bakar et al. 2014). 


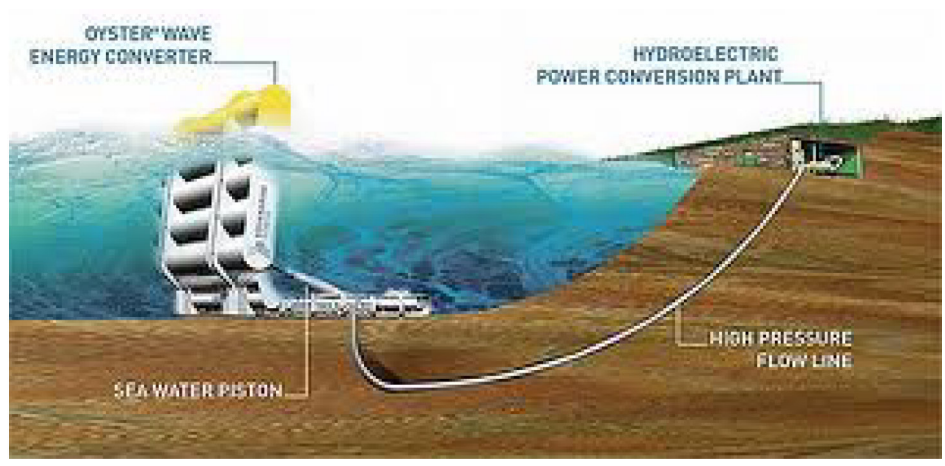

FIGURE 13. Oyster, oscillating flap WEC (Whittaker \& Folley 2012)

For this study, we assume that the design of the flap is a cylinder with a two-meter diameter hinged to the seabed, such as shown in Figure 14. Assume that the value of the parameters in (15) are $m=I+I_{a}=1$, $c=\Lambda+B_{r}=0.01, k_{p}=k=2$ and $B_{v}=0.1$.

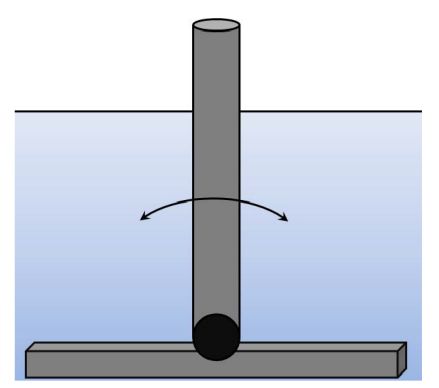

FIGURE 14. Simple cylinder oscillating flap WEC

The system's impulse response such as in Figure 15 is simulated by using the fourth-order Runge Kutta method, with the initial displacement of 0.1 . The impulse response is simulated for 500 seconds, with the sampling interval of 0.1 second. First, we transformed the impulse response using the CWT (Figure 16).
IRF

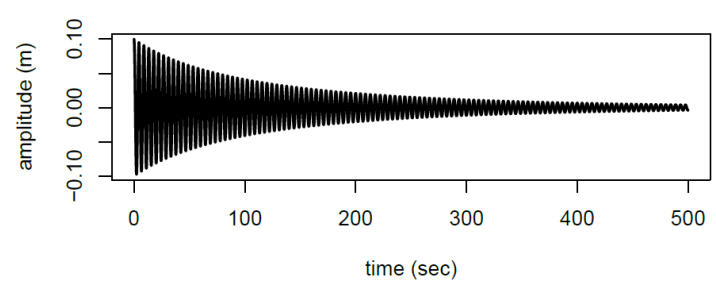

(a) First 500 seconds
IRF

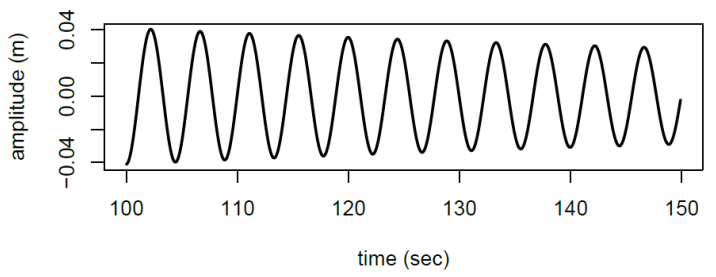

(b) Samples of 100 to 150 second

FIGURE 15. Time series of the impulse response (IRF) function for the OFWEC system with an impulse input 


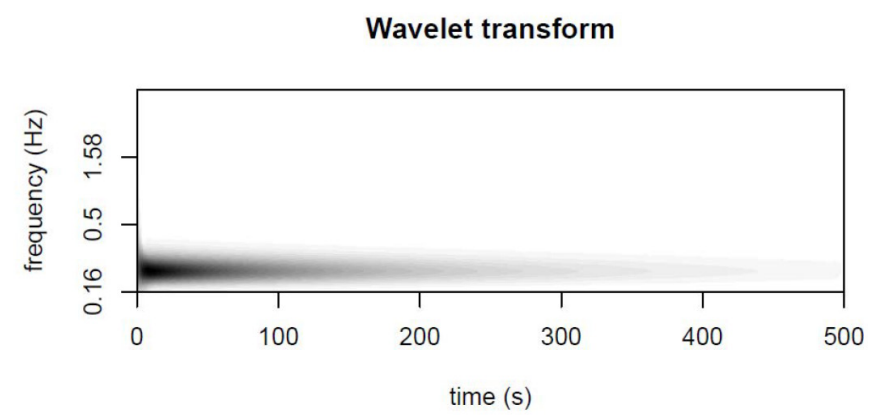

FIGURE 16. CWT of the impulse response (IRF) for the OFWEC system with an impulse input

The estimated instantaneous frequency from the wavelet ridge for the OFWEC system in Figure 17(a) is constant over time. The estimated instantaneous envelope for this system also fits the impulse response's peak (Figure 17(b)). From the wavelet skeleton, we reconstruct the impulse response and based on Figure 18, where it is shown that the estimation fits the theoretical impulse response of the OFWEC.
Instantaneous Frequency

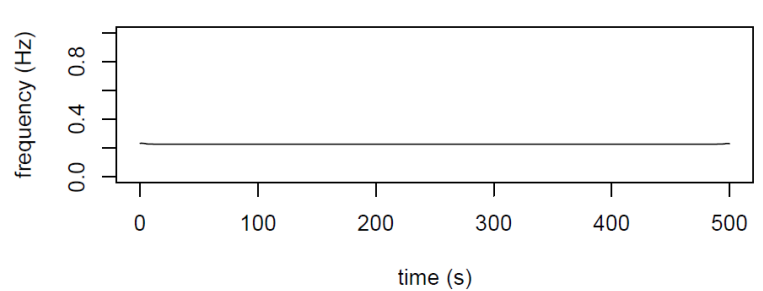

(a) Instantaneous frequency of the impulse response

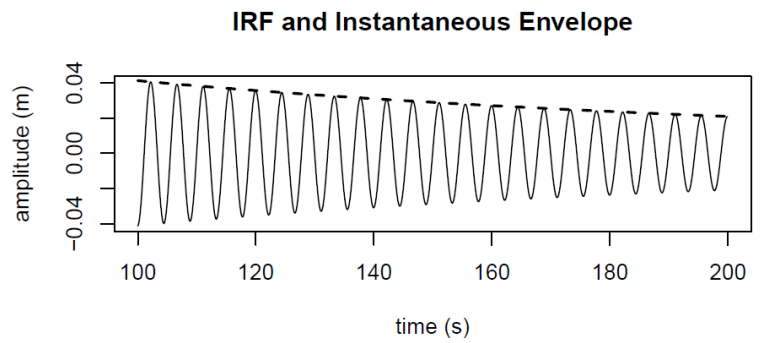

(b) Actual impulse response (full line) and instantaneou envelope (dashed line)

FIGURE 17. Wavelet estimation for the OFWEC system with an impulse input

IRF

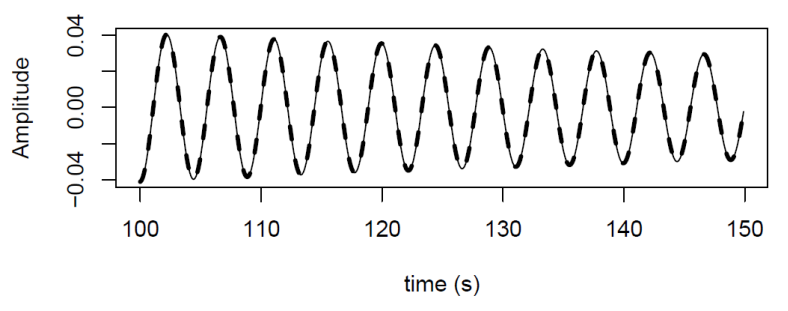

FIGURE 18. Theoretical impulse response (full line) and estimated impulse response (dashed line) for the OFWEC system with an impulse input from 100 to 150 seconds 


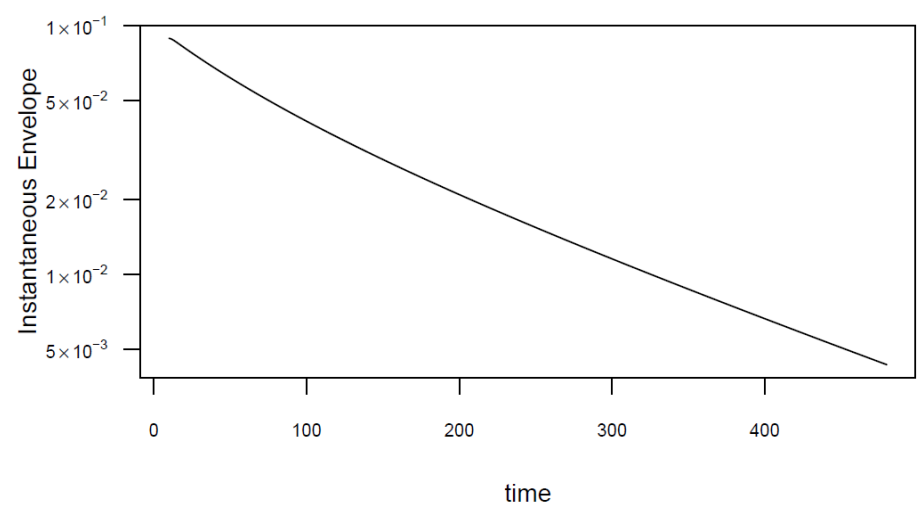

FIGURE 19. The semi-logarithmic plot of the instantaneous envelopes against times for the OFWEC system with an impulse input

From Figure 19, we can see that the damping of the OFWEC system depends on time. This is because the semi-logarithmic plot of the instantaneous envelope is not quite linear. Hence, the estimate for damping at time $t$ can only be found by calculating the tangent slope of the semi-logarithmic plot at time $t$. Based on the estimated backbone curve of this OFWEC system in Figure 20, we can say that, for the OFWEC system, the response amplitude does not depend on the frequency.

\section{Estimated Backbone}

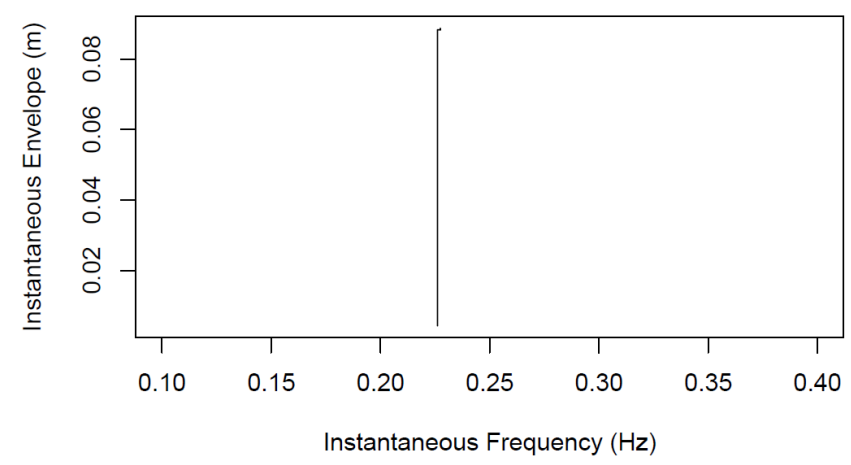

FIGURE 20. Estimated backbone curves for the OFWEC system with an impulse input

The RDT does capture the impulse response of this system when the wave tank input is used. Figure 21 shows that the theoretical impulse response is quite similar to the one captured by the RDT for the OFWEC systems with a wave tank input. It is shown in Figure 22 that the estimated backbone curve for the OFWEC system with tank input which is almost similar to the estimated backbone curve for the OFWEC system with impulse input show in Figure 20.

\section{NONLINEAR SYSTEMS WITH NOISE}

Table 1 shows the comparison between the Wavelet 
and Hilbert estimation of instantaneous envelope and frequency. For this comparison, the impulse response was polluted with three different levels of white noise where the standard deviations are 0.005 (low noise), 0.01 (medium noise) and 0.025 (high noise) for each level, respectively. The comparison between both approaches when the impulse response was not polluted by noise was also provided in Table 1 . The root-meansquare error (RMSE) was used to assess each approach's performance in estimating those instantaneous modal parameters, where lower RMSE values pointed out that the estimates are closer to the actual values.

RDT

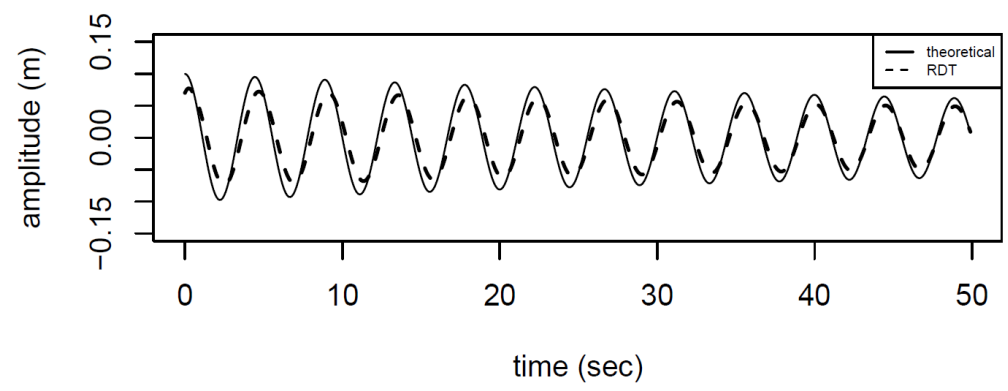

FIGURE 21. Impulse response (IRF) captured by the RDT for the OFWEC system with a wave tank input

\section{Estimated Backbone}

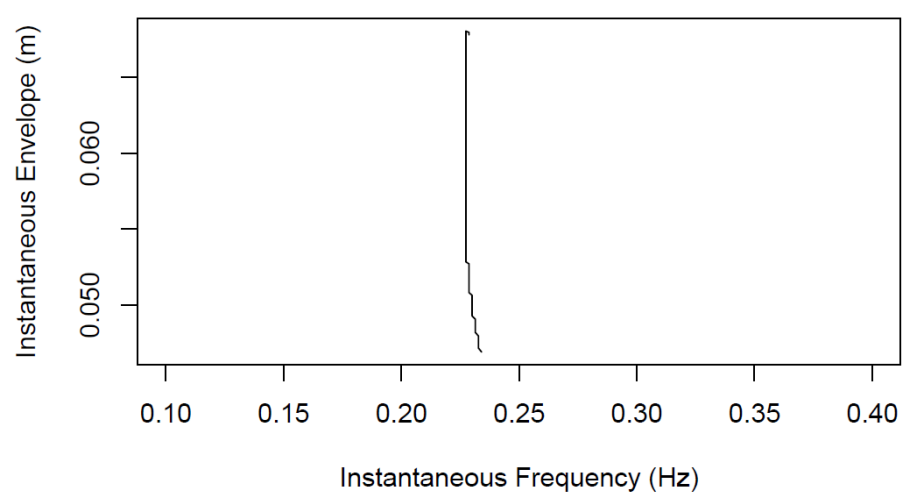

FIGURE 22. Estimated backbone curves for the OFWEC system with a wave tank input

It is shown that the wavelet approach was better in estimating the instantaneous frequency compared to the Hilbert approach when the impulse response was either polluted or not by the noise, except when the impulse response of the OFWEC system was polluted by high-level noise. Meanwhile, the Hilbert approach was better on estimating the instantaneous envelope, except when noises polluted the Duffing system's impulse response. 
TABLE 1. RMSE for Wavelet (WT) and Hilbert (HT) estimates of the instantaneous modal parameters for Duffing, Van der Pol and OFWEC systems

\begin{tabular}{|c|c|c|c|c|c|c|c|c|c|}
\hline \multirow{2}{*}{ System } & \multirow{2}{*}{ RMSE } & \multicolumn{2}{|c|}{ No noise } & \multicolumn{2}{|c|}{ Low noise, $\mathrm{s}=0.005$} & \multicolumn{2}{|c|}{ Medium noise, $\mathrm{s}=0.01$} & \multicolumn{2}{|c|}{ High noise, $\mathrm{s}=0.025$} \\
\hline & & WT & HT & WT & HT & WT & HT & WT & HT \\
\hline \multirow[b]{2}{*}{ Duffing } & $\begin{array}{l}\text { Instantaneous } \\
\text { Envelope }\end{array}$ & 0.00460 & 0.00351 & 0.00484 & 0.00651 & 0.00517 & 0.01132 & 0.00653 & 0.02638 \\
\hline & $\begin{array}{l}\text { Instantaneous } \\
\text { Frequency }\end{array}$ & 0.00268 & 0.00563 & 0.00268 & 0.00600 & 0.00272 & 0.01458 & 0.19132 & 0.21992 \\
\hline \multirow[b]{2}{*}{ Van der Pol } & $\begin{array}{l}\text { Instantaneous } \\
\text { Envelope }\end{array}$ & 0.07097 & 0.04316 & 0.07098 & 0.04362 & 0.07099 & 0.04466 & 0.07106 & 0.05086 \\
\hline & $\begin{array}{l}\text { Instantaneous } \\
\text { Frequency }\end{array}$ & 0.00101 & 0.01086 & 0.00101 & 0.01072 & 0.00104 & 0.01061 & 0.00108 & 0.01061 \\
\hline \multirow{2}{*}{$\begin{array}{l}\text { OFWEC } \\
\text { (case } \\
\text { study) }\end{array}$} & $\begin{array}{l}\text { Instantaneous } \\
\text { Envelope }\end{array}$ & 0.03652 & 0.03619 & 0.03651 & 0.03595 & 0.03640 & 0.03504 & 0.03292 & 0.03082 \\
\hline & $\begin{array}{l}\text { Instantaneous } \\
\text { Frequency }\end{array}$ & 0.00150 & 0.00614 & 0.01570 & 0.01795 & 0.09638 & 0.25450 & 1.14803 & 0.54056 \\
\hline
\end{tabular}

\section{CONCLUSION AND DISCUSSION}

This study has shown that the wavelet ridge can be used to identify nonlinearities in oscillating systems. It can also be used to categorize the type of nonlinearity of the system. Using the information on the system's instantaneous envelope and instantaneous frequency, which are estimated from the wavelet ridge and wavelet skeleton, the parameters such as the damping ratio and the nonlinear coefficients can be estimated. Based on the information found from these estimates, the parameters of the nonlinear system, such as the damping ratio and the nonlinear coefficients can be approximated.

In the cases of both the Duffing and the Van der Pol weakly nonlinear oscillators, the wavelet approach capable of identifying the system's parameter given that we know the type of that system. However, the wavelet approach is not suitable to estimate the heavily nonlinear system's parameters even though it can determine the nonlinearity of the systems. This is based on our investigation, where the wave tank signals were used as the input force on the oscillators. The results show that the RDT does not converge and so does not lead to capturing the impulse response of the Duffing and the Van der Pol oscillators. Presumably, this is because both nonlinear oscillators' system response to forcing is chaotic (Strogatz 2000).

For the case study, the RDT does capture the impulse response for the OFWEC, and there is no suggestion of a chaotic response. When the impulse response was polluted with noise, the wavelet approach was better in estimating the instantaneous frequency than the Hilbert approach, except for the OFWEC system with high-level noise. However, the Hilbert approach was better at estimating the instantaneous envelope compared to the wavelet technique, except for the Duffing system.

Overall, the wavelet method does provide useful insight into the process through the wavelet ridge and is recommended for nonlinear system identification, especially if the RDT can be used to capture the impulse response. This study had shown that the wavelet approach is useful when the form of the system is unknown and have better accuracy for estimating the instantaneous frequency even when the impulse responses were polluted with noise.

\section{ACKNOWLEDGEMENTS}

The authors would like to express great gratitude to Universiti Kebangsaan Malaysia (GGPM-2017-124) and 
the Ministry of Education, Malaysia (FRGS/1/2019/STG06/ $\mathrm{UKM} / 02 / 4$ ) for the allocation of the research grant and the facilities used for this research.

\section{REFERENCES}

Bakar, M.A.A., Green, D.A., Metcalfe, A.V. \& Ariff, N.M. 2014. Unscented Kalman filtering for wave energy converters system identification. AIP Conference Proceedings: Proceedings of the $3 \mathrm{rd}$ International Conference on Mathematical Sciences 1602: 304-310.

Bakar, M.A.A., Green, D.A., Metcalfe, A.V. \& Najafian, G. 2013. Comparison of heaving buoy and oscillating flap wave energy converters. AIP Conference Proceedings: Proceedings of the 20th National Symposium on Mathematical Sciences 1522: 86-101.

Bakar, M.A.A., Green, D.A. \& Metcalfe, A.V. 2012. Comparison of spectral and wavelet estimators of transfer function for linear systems. East Asian Journal on Applied Mathematics 2(3): 214-237.

Carmona, R., Torrésani, B., Whitcher, B., Wang, A., Hwang, W.L. \& Lees, J.M. 2018. Rwave: Time-Frequency Analysis of 1-D Signals. R package version 2.4-8.

Carmona, R., Hwang, W.L. \& Torrésani, B. 1998. Practical Time-Frequency Analysis: Gabor and Wavelet Transforms, with an Implementation in S. New York: Academic Press.

Carmona, R., Hwang, W.L. \& Torrésani, B. 1997. Characterization of signals by the ridges of their wavelet transforms. IEEE Transactions on Signal Processing 45(10): 2586-2590.

Feldman, M. 1994. Non-linear system vibration analysis using Hilbert transform--I. Free vibration analysis method 'Freevib'. Mechanical Systems and Signal Processing 8(2): 119-127.

Folley, M., Whittaker, T. \& Van’t Hoff, J. 2007. The design of small seabed mounted bottom hinged wave energy converters. 7th European Wave and Tidal Energy Conference, Porto, Portugal. 11-13 September.

Gouttebroze, S. \& Lardies, J. 2001. On using the wavelet transform in modal analysis. Mechanics Research Communications 28(5): 561-569.

Hardle, W., Kerkyacharian, G., Picard, D. \& Tsybakov, A. 1998. Wavelets, Approximation and Statistical Applications. New York: Springer-Verlag.

Kijewski, T. \& Kareem, A. 2003. Wavelet transforms for system identification in civil engineering. Computer-Aided Civil and Infrastructure Engineering 18(5): 339-355.

Lin, C.S. \& Lin, M.H. 2020. System identification from stationary ambient response using wavelet analysis with variable modal scales. Archive of Applied Mechanics. Online First https://link.springer.com/article/10.1007\%2 Fs00419-020-01792-2.

Londoño, J.M., Neild, S.A. \& Cooper, J.E. 2015. Identification of backbone curves of nonlinear systems from resonance decay responses. Journal of Sound and Vibration 348: 224-238.
McCusker, J.R., Danai, K. \& Kazmer, D.O. 2010. Validation of dynamic models in the time-scale domain. Journal of Dynamic Systems, Measurement, and Control 132(6): 061402 .

Mohammed, S.A., Bakar, M.A.A. \& Ariff, N.M. 2020. Volatility forecasting of financial time series using wavelet based exponential generalized autoregressive conditional heteroscedasticity model. Communications in Statistics Theory and Methods 49(1): 178-188.

Moradi, L., Mohammadi, F. \& Baleanu, D. 2019. A direct numerical solution of time-delay fractional optimal control problems by using Chelyshkov wavelets. Journal of Vibration and Control 25(2): 310-324.

Morison, J., Johnson, J. \& Schaaf, S. 1950. The force exerted by surface waves on piles. Journal of Petroleum Technology 2(5): 149-154.

Nayfeh, A.H. 2008. Perturbation Methods. Weinheim: Wiley$\mathrm{VCH}$.

Olsson, D.M. \& Nelson, L.S. 1975. The Nelder-Mead simplex procedure for function minimization. Technometrics 17(1): 45-51.

Perez-Ramirez, C.A., Jaen-Cuellar, A.Y., Valtierra-Rodriguez, M., Dominguez-Gonzalez, A., Osornio-Rios, R.A., RomeroTroncoso, R.D.J. \& Amezquita-Sanchez, J.P. 2017. A twostep strategy for system identification of civil structures for structural health monitoring using wavelet transform and genetic algorithms. Applied Sciences 7(2): 111.

Pernot, S. \& Lamarque, C.H. 2001. A wavelet-galerkin procedure to investigate time-periodic systems: Transient vibration and stability analysis. Journal of Sound and Vibration 245(5): 845-875.

Pirboudaghi, S., Tarinejad, R. \& Alami, M.T. 2018. Damage detection based on system identification of concrete dams using an extended finite element-wavelet transform coupled procedure. Journal of Vibration and Control 24(18): 42264246.

Ruzzene, M., Fasana, A., Garibaldi, L. \& Piombo, B. 1997. Natural frequencies and dampings identification using wavelet transform: Application to real data. Mechanical Systems and Signal Processing 11(2): 207-218.

Spina, D., Valente, C. \& Tomlinson, G. 1996. A new procedure for detecting nonlinearity from transient data using the Gabor transform. Nonlinear Dynamics 11(3): 235-254.

Staszewski, W.J. 2000. Analysis of non-linear systems using wavelets. Proceedings of the Institution of Mechanical Engineers - Part C - Journal of Mechanical Engineering Science 214(11): 1339-1353.

Staszewski, W.J. 1998. Identification of non-linear systems using multi-scale ridges and skeletons of the wavelet transform. Journal of Sound and Vibration 214(4): 639-658.

Staszewski, W.J. 1997. Identification of damping in MDOF systems using time-scale decomposition. Journal of Sound and Vibration 203(2): 283-305.

Strogatz, S.H. 2000. Nonlinear Dynamics and Chaos: With Applications to Physics, Biology, Chemistry, and Engineering. New York: CRC Press. 
Swaidan, W. \& Hussin, A. 2016. Haar wavelet method for constrained nonlinear optimal control problems with application to production inventory model. Sains Malaysiana 45(2): 305-313.

Wang, Y. 2017. A new concept using LSTM neural networks for dynamic system identification. 2017 American Control Conference (ACC), Seattle, WA, USA. 24-26 May. pp. 5324-5329.

Whittaker, T. \& Folley, M. 2012. Nearshore oscillating wave surge converters and the development of oyster. Philosophical Transactions of The Royal Society A 370: 345-364.

Woo, J., Park, J., Yu, C. \& Kim, N. 2018. Dynamic model identification of unmanned surface vehicles using deep learning network. Applied Ocean Research 78: 123-133.

Yu, Y., Shenoi, R.A., Zhu, H. \& Xia, L. 2006. Using wavelet transforms to analyze nonlinear ship rolling and heave-roll coupling. Ocean Engineering 33(7): 912-926.

Zhang, G., Tang, B. \& Chen, Z. 2019. Operational modal parameter identification based on PCA-CWT. Measurement 139: $334-345$
Mohd Aftar Abu Bakar \& Noratiqah Mohd Ariff* Department of Mathematical Sciences

Faculty of Science and Technology

Universiti Kebangsaan Malaysia

43600 UKM Bangi, Selangor Darul Ehsan

Malaysia

Andrew V. Metcalfe \& David A. Green

School of Mathematical Sciences

Faculty of Engineering, Computer and Mathematical Sciences University of Adelaide

5005, South Australia

Australia

*Corresponding author; email: tqah@ukm.edu.my

Received: 27 August 2020

Accepted: 3 March 2021 